・研究报告・

\title{
利用花青素可视化跟踪表达系统快速篮选表达 Cry1Ab/c基因的转基因玉米
}

\author{
巴超杰 ${ }^{1,2 \dagger}$, 薛静 ${ }^{1 \dagger}$, 陈绪清 ${ }^{1}$, 杨凤萍 ${ }^{1}$, 张立全 ${ }^{1}$, 李向龙 ${ }^{1}$, 张晓东 ${ }^{\text {* }}$ \\ ${ }^{1}$ 北京市农林科学院, 北京农业生物技术研究中心, 北京 100097 $^{2}$ 首都师范大学生命科学学院, 北京 100037
}

\begin{abstract}
摘要 以草甘膦抗性基因Epsps为标记基因, 在原核Kan ${ }^{r}$ 基因两侧引入Cre(环化重组酶)基因识别的Lox-P位点, 同时以编 码花青素合成转录因子的 $B i$ 和 $C /$ / 基因为可视化选择报告基因, 构建了 $\mathrm{Bt}$ 杀虫蛋白基因 $C r y 1 A b / c$ 的可视化跟踪表达载体 pBAC9017。用PDS1000/He基因枪转化玉米(Zea mays)自交系501的幼胚和肧性愈伤组织, 获得147个草甘膦抗性的玉米 再生植株。其中106棵植株获得了结实种子, 16棵植株的结实种子有紫红色花青素基因的表达。经PCR检测表明, 外源 $C r y 1 A b / c$ 基因已经整合到玉米的基因组中。转基因植株种子蛋白粗提物用BT-Cry1Ab/1Ac金标免疫检测试纸条和ELISA检 测, 结果表明, Cry $1 \mathrm{Ab} / \mathrm{c}$ 在部分转基因植株后代中表达。
\end{abstract}

关键词 花青素, Bt, Cry1Ab/c, 玉米, 转基因

巴超杰, 薛静, 陈绪清, 杨风萍, 张立全, 李向龙, 张晓东 (2013). 利用花青素可视化跟踪表达系统快速筛选表达 $\operatorname{Cry} 1 \mathrm{Ab} / \mathrm{c}$ 基因的转基因玉米. 植物学报 48, 59-64.

玉米(Zea mays)用途广泛, 可作为食物、饲料和 工业原料, 其种植面积居世界第3位。而虫害是玉米 的第一大害, 可使玉米减产 $20 \%-30 \%$ 。其中玉米螟 等鳞翅目害虫是我国玉米的主要钻蛀性害虫, 严重时 导致玉米心叶破碎, 延迟抽穗, 影响植株生长, 降低 玉米品质(孙宝刚等, 2010)。苏云金芽狍杆菌(Bacillus thuringiensis, Bt) 是目前国内外应用最广泛且最有效 的微生物杀虫剂, 其杀虫蛋白基因(又称Cry基因)编 码产生杀虫晶体蛋白 (insecticidal crystal proteins, ICPs)。Crickmore等(1998)根据氨基酸同源性对杀虫 晶体蛋白进行分级分类, 形成了一个开放式分类系 统。该系统共分为 4 级, 同源性在 $45 \%$ 以下为第一等 级; 同源性介于 $45 \%-78 \%$ 之间为第二等级; 同源性 介于 $78 \%-95 \%$ 之间为第三等级; 同源性在 $95 \%$ 以上 的是第四等级。截至2011年9月, 全球共发现近600 多种 Cry基因(http://www.lifesci.sussex.ac.uk/home/ Neil_Crickmore/Bt/index.html), 其编码的杀虫蛋白 可杀鳞翅目、鞘翅目和双翅目等60多种昆虫。Cry $1 \mathrm{~A}$ 毒蛋白对鳞翅目害虫具有很高的毒性(Sauka et al.,
2007)。

花青素是一类广泛存在于植物中的水溶性天然 色素, 花青素的生物合成受结构基因和调控基因的共 同控制, 调控基因的表达使花青素在植物细胞内积 累, 并表现出色彩的变化(Zhang et al., 2012)。因易 于观察, 花青素可作为报告基因, 用于转基因植物研 究。在玉米中, 调控花青素合成主要有2类转录因子, 一种是与MYB相关的转录因子; 一种是与 $\mathrm{bHLH}$ 相关 的转录因子(Sharma et al., 2011)。Bi基因编码 bHLH 类蛋白, 调节成熟植物组织(如叶鞘和苍叶)的光谱颜 色(Radicella et al., 1991)。C/基因编码MYB类蛋白, 主要调控糊粉层和胚的色素合成(Chen and Coe, 1977)。 $B i$ 和 $C /$ 基因编码的转录因子相互作用共同调 控花青素的合成(宫硖等, 2011)。本研究以编码花青 素合成转录因子的 $B i$ 和 $C /$ 基因作为可视化选择报告 基因, 以期更快速有效地篮选转基因阳性植株。

本实验室在前期研究中, 采用基因枪转化方法获 得了转 $C r y 1 A b / c$ 的玉米植株, 有3株转基因 $\mathrm{T}_{1}$ 代玉米 植株用Bt金标试纸检测呈阳性(王艳辉等, 2010)。但

收稿日期: 2012-02-09; 接受日期: 2012-07-30

基金项目: 国家十一五转基因重大专项(No.2008ZX08003-001)

十共同第一作者。

* 通讯作者。E-mail: zhangxiaodong@baafs.net.cn 
是在后期的检测中发现，由于存在嵌合体问题，该转 基因玉米在繁殖几代后, 未能筛选到转基因植株。即 外源基因 Cry $1 A b / c$ 由于不稳定而丢失, 而且对后代 植株进行检测的工作量很大。本研究将人工合成优化 的Cry $1 A b / c$ 插入到含有抗除草剂篎选标记基因的载 体中, 以花青素合成转录因子 $B i$ 和 $C /$ 基因为可视化选 择报告基因, 成功构建了植物表达载体pBAC9017, 并用基因枪法将其转入到玉米中, 以期能通过籽粒颜 色更加直观有效地篮选并获得外源基因稳定高效表 达的转基因植株。

\section{1 材料与方法}

\section{1 实验材料}

\subsection{1 受体材料}

玉米(Zea mays L.)优良自交系501由北京市农林科学 院玉米研究中心陈刚研究员提供。

\subsection{2 质粒}

质粒pBAC9008和pBAC165为本实验室保存。

\subsection{3 生化试剂}

Taq DNA聚合酶、 $\mathrm{T}_{4}$ DNA连接酶和卡那霉素(Kan)等 试剂均购自宝生物工程(大连)有限公司 (TaKaRa)。 DNA回收试剂盒购自Axygen公司。大肠杆菌感受态 $\mathrm{DH} 5 \mathrm{\alpha}$ 购自天根生化科技(北京)有限公司。HindIII、 EcoRI等限制性内切酶购自 New England Biolabs (NEB)或TaKaRa公司。普通生化试剂购自Sigma公司 或使用国产品牌。基因枪型号为PDS-1000/ $\mathrm{He}$ (购自 BioRad)。引物合成及测序由上海生工生物工程技术 服务有限公司完成。

\section{2 实验方法}

\subsection{1 表达载体的构建}

密码子优化后的 Cry $1 A b / c$ 基因, 由上海生工公司合 成。用BamHI和Sacl酶切后插入到含有E35S启动子 和玉米HSP70 intron以及Nos终止子序列的中间载体 $\mathrm{pBAC} 154$, 获得 $E 35 S$ 启动子和玉米HSP70 intron驱 动的 Cry1Ab/c 基因表达框架中间载体pBAC165。用 $H i n d I I I$ 和 $E c o R I$ 从 pBAC165切下该区段, 插入到可视 化跟踪表达pBAC9008的HindIII和ECORI位点之间。
即获得目的基因 $C r y 1 A b / c$ 的可视化跟踪表达载体 pBAC9017(图1)。

\subsection{2 基因枪转化}

基因枪转化方法及所用培养基参考王艳辉等(2010) 所述方法。

\subsection{3 转基因植株的PCR 检测}

根据 $C r y 1 A b / c$ 基因片段设计引物。上游引物为 Cry1 $\mathrm{Ab} / \mathrm{cF}$, 5'-ACCCAAACATCAACGAGTGC-3', 下游 引物为 Cry $1 \mathrm{Ab} / \mathrm{cR}, 5^{\prime}$-TAGTTCTGGACGGCGAAGAGTG-3'，扩增的目的片段大小为 $1033 \mathrm{bp}$ 。用改 良CTAB法提取转基因玉米叶片基因组DNA。以非转 基因植株为阴性对照, pBAC9017质粒为阳性对照, $\mathrm{dd}_{2} \mathrm{O}$ 为空白对照, 对转基因植株进行PCR 检测。 PCR 反应体系为 $1 \mu L D N A$ 模板, $5 \mu \mathrm{L} 10 \times P C R$ Buffer, $4 \mu \mathrm{L}$ dNTPs $\left(2.5 \mathrm{mmol} \cdot \mathrm{L}^{-1}\right), 1 \mu \mathrm{LCry} 1 \mathrm{Ab} / \mathrm{cF}(10$ $\left.\mu \mathrm{mol} \cdot \mathrm{L}^{-1}\right), 1 \mu \mathrm{LCry} 1 \mathrm{Ab} / \mathrm{cR}\left(10 \mu \mathrm{mol} \cdot \mathrm{L}^{-1}\right), 0.5 \mu \mathrm{L}$ Taq DNA聚合酶 $\left(5 \mathrm{U} \cdot \mu \mathrm{L}^{-1}\right), 37.5 \mu \mathrm{LddH}_{2} \mathrm{O}$ 。反应程序如 下： $94^{\circ} \mathrm{C}$ 预变性 5 分钟; $94^{\circ} \mathrm{C} 30$ 秒, $55^{\circ} \mathrm{C} 30$ 秒, $72^{\circ} \mathrm{C} 60$ 秒, 38 个循环; $72^{\circ} \mathrm{C}$ 延伸 10 分钟。反应产物用 $0.8 \%$ 琼脂糖凝胶电泳检测。

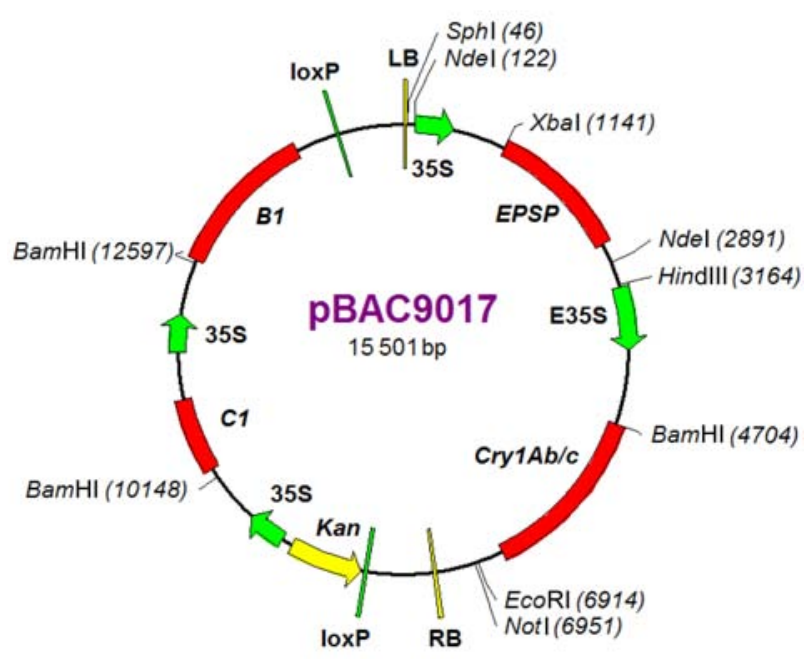

图1 Cry1Ab/c可视化跟踪表达载体pBAC9017

Figure 1 Visual tracking expression vector pBAC9017 of Cry1Ab/c 


\subsection{4 转基因植株的RT-PCR 检测}

用天根生化科技(北京)有限公司的总RNA提取试剂盒 提取转基因玉米叶片RNA。以Oligo dT18 Primer作为 随机引物, 使用TaKaRa的M-MLV进行逆转录后, 以 $\mathrm{Cry} 1 \mathrm{Ab} / \mathrm{cF}$ 和 Cry $1 \mathrm{Ab} / \mathrm{cR}$ 为引物, 扩增片段大小为 $1033 \mathrm{bp}$ 。

\subsection{5 转基因植株的金标免疫检测}

本实验选用美国Agdia公司提供的BT-Cry $1 \mathrm{Ab} / 1 \mathrm{Ac}$ 转 基因检测试纸条, 测定转化植株种子中Bt毒蛋白的表 达。具体操作方法参照说明书。

\subsection{6 转基因植株的ELISA检测}

酶联免疫吸附测定(ELISA)用于检测转基因植株种子 中的Cry1 Ab/c蛋白。本实验选用美国Agdia公司提供 的Bt(Cry1Ab/c)ELISA试剂盒。具体操作方法按其说 明书进行。

\section{2 结果与讨论}

\section{1 转基因植株的获得}

首先大量提取和纯化质粒载体pBAC9017, 浓度为 1 $\mu \mathrm{g} \cdot \mu \mathrm{L}^{-1}$ 。然后制备基因枪转化所用的子弹。先用 PSD1000/He系统对玉米501的幼胚或胚性愈伤组织 进行转化, 再用草甘膦除草剂进行篮选分化, 经室内 壮苗后共得到147个 $T_{0}$ 代再生植株, 将其移栽到温
室。最终统计有106棵植株获得结实种子, 其中16棵 植株的后代有紫红色花青素基因的表达(图2)。

\section{$2.2 \mathrm{~T}_{0}$ 代转基因植株的PCR检测}

用Cry1 Ab/cF和Cry1Ab/cR引物对16株有紫红色花青 素基因表达的 $\mathrm{T}_{0}$ 代转基因植株的基因组DNA进行 PCR 扩增。图3示部分检测结果。由图3可知: 1-8泳 道所对应的转基因植株均扩增出了长度为 $1033 \mathrm{bp}$ 的特异条带, 说明1-8泳道所对应的转基因植株都含 有 Cry $1 \mathrm{Ab} / \mathrm{c}$ 基因。通过PCR 初步篮选, 结果表明外源 基因Cry1Ab/c 已经整合到玉米的基因组中。

\section{$2.3 \mathrm{~T}_{1}$ 代转基因植株的RT-PCR检测}

用Cry1 Ab/cF和Cry1Ab/cR引物对 $T_{1}$ 代有紫红色花青 素基因表达的植株进行RT-PCR 检测。图4示部分检 测结果。如图4所示, 1-7和9-11泳道所对应的转基因 植株表达了Cry1 Ab/c基因。在有紫红色花青素基因表 达的植株中外源基因 Cry $1 \mathrm{Ab} / \mathrm{c}$ 转录表达的阳性率达 到 $89 \%$ 。

\section{$2.4 \mathrm{~T}_{1}$ 代转基因玉米中 Bt 基因表达蛋白的金标试 纸检测分析}

选取 $T_{1}$ 代RT-PCR 检测为阳性植株的种子进行金标试 纸检测。结果(图5)显示, 阴性对照只在质控区出现1 条红色条带, 检测区未出现红色条带; 样本1、3、4、 5、7和8中均在检测区和质控区各出现1条红色条带,
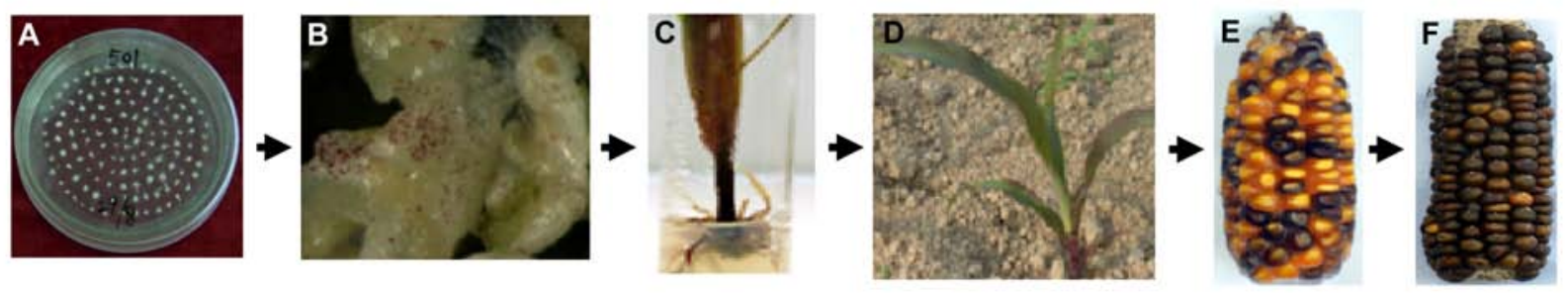

图2 转基因玉米植株的分化及田间移栽
(A) 诱导愈伤组织;
(B) 花青素基因的瞬时表达;
; (C) 转化再生植株;
(D) 植株移栽;
(E) To代结实果穗;
(F) $T_{1}$ 代果穗花青素纯合表达

Figure 2 Differentiation of transformed maize plants and transplanting

(A) Calli inducted on inductive medium; (B) Expression of anthocyanin genes; (C) Transgenic maize plantlet; (D) Transplanting;

(E) Seeds of $T_{0}$ transgenic; (F) Seeds of $T_{1}$ transgenic 


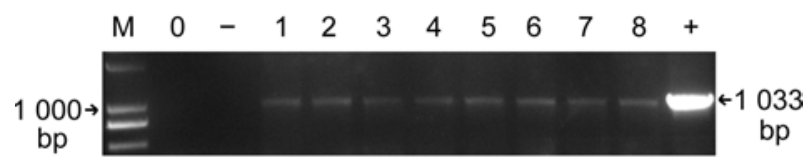

图3 转基因玉米 $\mathrm{T}_{0}$ 代植株的PCR检测

M: DL2000 marker; +: 质粒(pBAC9017); 0: 水; -: 非转基因 植株; 1-8: 部分转基因再生植株。

Figure $3 \mathrm{PCR}$ analysis of $\mathrm{T}_{0}$ transgenic maize plants M: DL2000 marker; +: Plasmid pBAC9017; 0: $\mathrm{ddH}_{2} \mathrm{O}$; -: Non-transgenic plant; 1-8: Some transgenic lines.

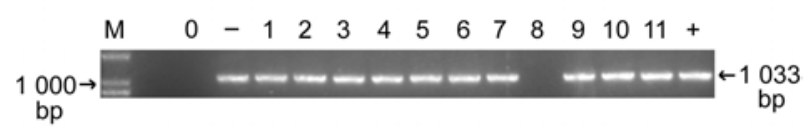

图4 转基因玉米 $\mathrm{T}_{1}$ 代植株的RT-PCR检测

M: DL2000 marker; +: 质粒(pBAC9017); 0: 水; -: 非转基因 植株; 1-11: 部分转基因再生植株。

Figure 4 RT-PCR analysis of $\mathrm{T}_{1}$ transgenic maize plants M: DL2000 marker; +: Plasmid pBAC9017; 0: $\mathrm{ddH}_{2} \mathrm{O}$; -: Non-transgenic plant; 1-11: Some transgenic lines.

结果为阳性。说明样本 $1 、 3 、 4 、 5 、 7$ 和 8 所对应的 转基因植株表达了Cry1Ab/c蛋白。

\section{$2.5 \mathrm{~T}_{1}$ 代转基因玉米中Bt 基因表达蛋白的ELISA 分析}

选取 $T_{1}$ 代RT-PCR 检测为阳性植株的种子进行ELISA 检测(图6)。每个样品设3次重复, 取平均值。一般视 大于阴性对照2.1倍的样本为阳性。由图7可知, 样本 $4 、 5 、 6 、 7 、 8 、 9 、 13 、 14$ 和15都远远大于阴性对 照的2.1倍, 表现为阳性, 证明这些植株表达了外源 Cry1Ab/c蛋白。用金标试纸和ELISA两种方法检测提 高了结果的可靠性。

\section{6 讨论}

转基因研究中获得转基因植株的数量取决于整合外 源基因到目标细胞的能力和分辨转基因植株的效率 (Bohorova et al., 1999), 因此报告基因的选择尤为 重要。近些年, 花青素调控因子受到越来越多的科研 工作者的关注。拟南芥(Arabidopsis thaliana)中的

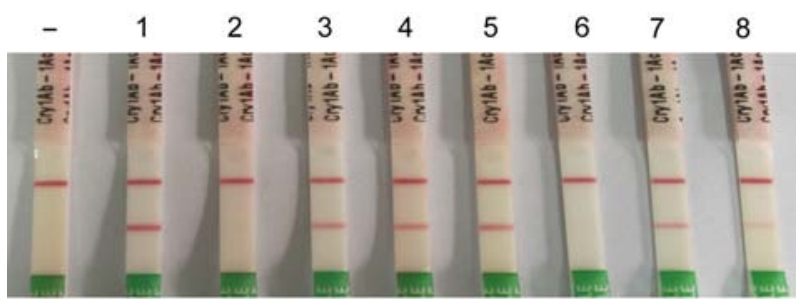

图5 转基因玉米 $\mathrm{T}_{1}$ 代植株的 $\mathrm{Bt}$ 金标试纸检测结果 -: 非转基因植株; 1-8: $\mathrm{T}_{1}$ 代转基因植株。

Figure $5 \mathrm{BT}-\mathrm{Cry} 1 \mathrm{Ab} / 1 \mathrm{Ac}$ analysis of $\mathrm{T}_{1}$ transgenic maize plants -: Non-transgenic plant; 1-8: $T_{1}$ transgenic plants.

A

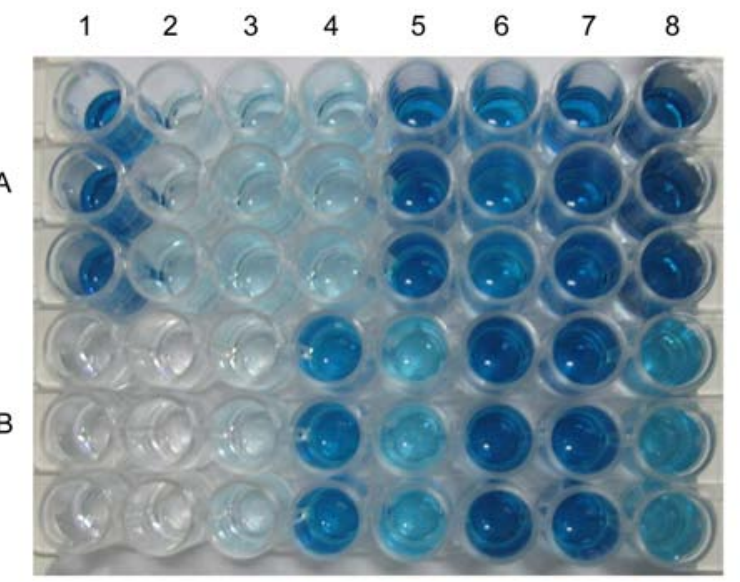

图6 转基因玉米植株外源Cry1 Ab/c蛋白ELISA结果 1B: 空白; 2B: 非转基因植株; 3B-8B, 1A-7A: $\mathrm{T}_{1}$ 代转基因植 株; 8A: 阳性对照。

Figure 6 ELISA of Cry1Ab/c protein in transgenic maize plants

1B: Blank; 2B: Non-transgenic maize; 3B-8B, 1A-7A: $T_{1}$ transgenic plants; 8A: Positive control.

$P A P 1$ 基因编码转录因子MYB75, 调控花青素的生物 合成, $P A P 1$ 基因在烟草(Nicotiana tabacum)细胞中 的表达导致细胞呈现暗红色(Zhou et al., 2008)。在组 织特异启动子的驱动下, $B-P e r u$ 和 $C 1$ 基因在小麦 (Triticum aestivum)多种组织中瞬时表达花青素 (Doshi et al., 2006)。花青素调控转录因子基因 $B p$ 和 C1在组织特异调控下使玉米呈现出紫色 (Liu and Petolino, 2006)。C1和B-Peru基因可以作为小麦和黑 小麦的可视化标记(Doshi et al., 2007)。花青素监控 系统增强了番茄(Lycopersicon esculentum)果实中 


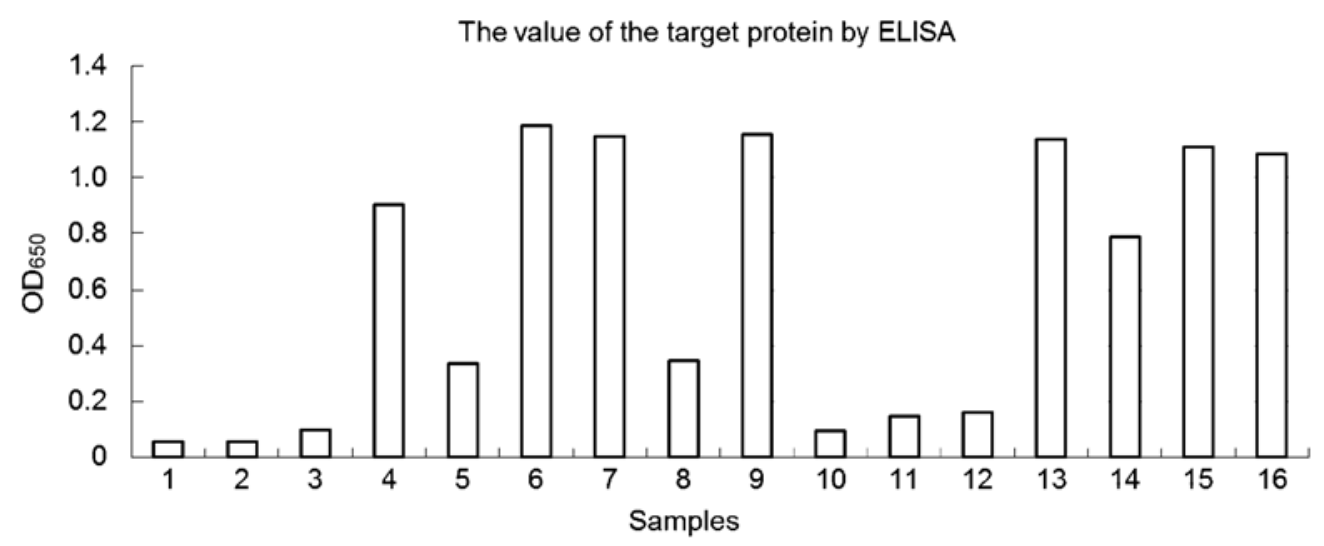

图7 转基因玉米植株Cry1Ab/c蛋白ELISA结果柱状图

1: 空白; 2: 非转基因植株; 3-15: $\mathrm{T}_{1}$ 代转基因植株; 16: 阳性对照。

Figure 7 ELISA histogram of Cry1 Ab/c protein in transgenic maize plants

1: Blank; 2: Non-transgenic maize; 3-15: $T_{1}$ transgenic plants; 16: Positive control.

病毒介导的基因沉默, 使其能够更有力地研究果实成 熟时的代谢网络(Orzaez et al., 2009)。苹果(Malus pumila)花青素合成转录因子MYB10基因可以作为苹 果、草莓(Gragaria ananassa)和马铃薯(Solanum tuberosum)转化的篎选标记基因, 代替卡那抗性基 因(Kortstee et al., 2011)。本实验以编码花青素合成 转录因子的 $B i$ 和 $C /$ / 基因作为可视化选择报告基因, 构 建了Cry1Ab/c的可视化跟踪表达载体pBAC9017, 进 而用基因枪法转化玉米, 从中挑选有紫红色花青素基 因表达的植株进行检测, 篮选出表达Cry $1 \mathrm{Ab} / \mathrm{c}$ 蛋白 的植株。这种可视化标记不需要对材料进行处理, 不 使用仪器观察, 肉眼即可辨别转基因植物, 便于快 速、大批量篮选转基因材料, 大大减少了工作量, 提 高了转基因植株的检测效率。

此外, 实验中发现存在嵌合体及转基因后代中有 基因沉默现象。因此必须对转基因植株的后代进行连 续跟踪检测, 以确保不丢失目的基因。随着不断加代, 对后代植株进行检测的工作量越来越大。可视化标记 的利用可以从玉米籽粒颜色直观观察转基因后代中 基因是否分离、纯合以及沉默, 从而间接反映出目的 基因的情况。这对于得到外源基因稳定表达的纯合的 转基因株系及后续的育种工作有重要的意义。

下一步将选择外源基因稳定表达的纯合的转基 因株系开展田间接虫实验, 进行抗玉米螟活性测定, 以检测转基因植株的抗虫效果。

\section{参考文献}

宫硖, 薛静, 张晓东 (2011). 植物花青素合成途径中的调控 基因研究进展. 生物技术进展 1, 381-390.

孙宝刚, 郑剑英, 戴福全, 袁世权, 徐海艳 (2010). 玉米蛽生 物防治技术. 吉林农业. (6), 84-84.

王艳辉, 陈旭清, 薛静, 张立全, 杨风萍, 李向龙, 张晓东 (2010). Cry1Ab/1Ac基因在转基因玉米中的表达研究. 分子 植物育种 8, 1-6.

Bohorova N, Zhang W, Julstrum P, Mclean S, Luna B, Brito RM, Diaz L, Ramos ME, Estanol P, Pacheco M, Salgado M, Hoisington D (1999). Production of transgenic tropical maize with crylAb and crylAc genes via microprojectile bombardment of immature embryos. Theor Appl Genet 99, 437-444.

Chen SM, Coe EH Jr (1977). Control of anthocyanin synthesis by the $C$ locus in maize. Biol Genet 15, 333-346.

Crickmore N, Zeigler DR, Feitelson J, Schnepf E, Van Rie J, Lereclus D, Baum J, Dean DH (1998). Revision of the nomenclature for the Bacillus thuringiensis pesticidal crystal proteins. Microbiol Mol Biol Rev 62, 807-813.

Doshi KM, Eudes F, Laroche A, Gaudet D (2006). Transient embryo-specific expression of anthocyanin in wheat. In Vitro Cell Dev Biol Plant 42, 432-438.

Doshi KM, Eudes F, Laroche A, Gaudet D (2007). Anthocyanin expression in marker free transgenic wheat and triticale embryos. In Vitro Cell Dev Biol Plant 43, 429-435.

Kortstee AJ, Khan SA, Helderman C, Trindade LM, Wu Y, 
Visser RGF, Brendolise C, Allan A, Schouten HJ, Jacobsen E (2011). Anthocyanin production as a potential visual selection marker during plant transformation. Transgenic Res 20, 1253-1264.

Liu YS, Petolino JF (2006). Pigmented maize seed via tissue-specific expression of anthocyanin pathway gene transcription factors. Mol Breeding 18, 57-67.

Orzaez D, Medina A, Torre S, Fernández-Moreno JP, Rambla JL, Fernández-del-Carmen A, Butelli E, Martin C, Granell A (2009). A visual reporter system for virus-induced gene silencing in tomato fruit based on anthocyanin accumulation. Plant Physiol 150, 11221134.

Radicella JP, Turks D, Chandler VL (1991). Cloning and nucleotide sequence of a cDNA encoding B-Peru, a regulatory protein of the anthocyanin pathway in maize. Plant Mol Biol 17, 127-130.
Sauka DH, Amadio AF, Zandomeni RO, Benintende GB (2007). Strategy for amplification and sequencing of insecticidal cry1A genes from Bacillus thuringiensis. Anton Van Leeuw 91, 423-430.

Sharma M, Cortes-Cruz M, Ahern KR, McMullen M, Brutnell TP, Chopra S (2011). Identification of the Pr1 gene product completes the anthocyanin biosynthesis pathway of maize. Genetics 188, 69-79.

Zhang B, Hu ZL, Zhang YJ, Li YL, Zhou S, Chen GP (2012). A putative functional MYB transcription factor induced by low temperature regulates anthocyanin biosynthesis in purple kale (Brassica oleracea var. acephala $\mathrm{f}$. tricolor). Plant Cell Rep 31, 281-289.

Zhou LL, Zeng HN, Shi MZ, Xie DY (2008). Development of tobacco callus cultures over expressing Arabidopsis PAP1/MYB75 transcription factor and characterization of anthocyanin biosynthesis. Planta 229, 37-51.

\title{
Rapid Screening of Cry1Ab/c Transgenic Maize Using an Anthocyanin Visualizing Track System
}

\author{
Chaojie $\mathrm{Ba}^{1,2 \dagger}$, Jing Xue ${ }^{1 \dagger}$, Xuqing Chen ${ }^{1}$, Fengping Yang ${ }^{1}$, Liquan Zhang ${ }^{1}$, Xianglong $\mathrm{Li}^{1}$, Xiaodong Zhang ${ }^{1^{*}}$ \\ ${ }^{1}$ Beijing Research Center for Agricultural Biotechnology, Beijing Academy of Agriculture and Forestry Sciences, Beijing \\ 100097, China; ${ }^{2}$ College of Life Sciences, Capital Normal University, Beijing 100037, China
}

\begin{abstract}
Bi}$ and $\mathrm{Cl}$ genes, encoding anthocyanin synthesis of transcription factor, were used as visual selection reporter genes, and the glyphosate-resistance gene EPSPS as a selective marker, to generate a visualizing track vector pBAC9017. We used this vector to transform Cry1Ab/c driven by an enhanced CaMV 35S (E35S) promotor, into immature embryos and embryonic callus of maize inbred line 501 by microprojectile bombardment. We obtained 147 transformed, and among 106 plants with harvested $T_{0}$ ears, 16 ears were decorated with mosaic purple seeds. PCR analysis showed that the $\mathrm{Cry} 1 \mathrm{Ab} / \mathrm{c}$ gene was integrated into the genome of maize. Extracts of seed protein were tested by BT-Cry1 Ab/1Ac immune-strip and ELISA, showing that Bt-Cry1 Ab/c gene was expressed in transgenic lines.
\end{abstract}

Key words anthocyanin, Bt, Cry1Ab/c, maize, transgenic

Ba CJ, Xue J, Chen XQ, Yang FP, Zhang LQ, Li XL, Zhang XD (2013). Rapid screening of Cry1Ab/c transgenic maize using an anthocyanin visualizing track system. Chin Bull Bot 48, 59-64.

\footnotetext{
${ }^{\dagger}$ These authors contributed equally in this paper.

*Author for correspondence. E-mail: zhangxiaodong@baafs.net.cn
} 